\title{
Soil-protective technologies as an important component of agricultural biologization in the conditions of the Central Polissia of Ukraine
}

\author{
N.N. Kravchuk ${ }^{*}$, R. B. Kropyvnytskyi, S. V. Zhuravel, T. V. Klymenko, and O.I. Trembitska \\ Polissia National University, Ukraine
}

\begin{abstract}
In article the comparison of traditional moldboard tillage and soil-protective efficiency of agrotechnologies is given in light gray forest soil. For more objective assessment indicators of soil fertility were defined in sowing of grain and a row crops. It is established that long (27 years) use of technologies which are based on moldboardless tillage in a crop rotation even on options without fertilization provided increase in maintenance of the general humus (mainly at the expense of fraction of the detritus), improvement of some agrophysical and water-physical indicators. Thus, the coefficient of structure degree increased by $16.4 \%$, the water resistance of units increased by $7.8-8.1 \%$, soil hardness decreased by $9.1-9.4 \mathrm{~kg} / \mathrm{cm} 2$, but soil density did not change significantly. The reserve of productive moisture in a layer of $0-30 \mathrm{~cm}$ at the time of crops of a winter wheat was $7.0 \mathrm{~mm}$ higher, and before harvesting - by $4.4 \mathrm{~mm}$ in comparison to an indicator on plowing. Before planting of potatoes the increase made $6.1 \mathrm{~mm}$, and before harvesting $-3.4 \mathrm{~mm}$ in comparison to control. The productivity of cultures did not concede observations at moldboardless tillage to plowing in recent years. However, the air-dry mass of weeds increased significantly in crops of wheat (by 20.9\%), and potatoes (by 26.4\%).
\end{abstract}

\section{Introduction}

The use of soil-protective agrotechnologies is connected with some risks (decrease in productivity, profitability, deterioration in a phytosanitary condition of fields), but is the perspective and necessary direction in the agricultural industry. The use of the specified technologies in the conditions of Polissia of Ukraine is rather relevant as soil covering of the region is provided by light-textured soils mainly that are characterized disadvantageous agrophysical and water physical properties. They have low resistance to anthropogenic loading and also low ability to maintain balanced condition of the main modes and properties of soil.

A significant amount of publications is devoted to impact assessment of the specified technologies of culture cultivation on indicators of fertility of zonal sod-podzolic soils [1, 2, $3]$. At the same time, their use on light gray and gray forest soils has a number of advantages. The last is connected with the fact that these soils have higher potential fertility and can

*Corresponding author: ekosoil@ukr.net 
become a good basis for use of soil-protective technologies in the system of organic production in a zone of Polissia of Ukraine $[1,2,4]$. The purpose of researches was to study the efficiency of agrotechnologies, which are based on a moldboardless of the main tillage of soil as an important component of forming of steady agroecosystems. Due to this, we set the tasks to analyze results of a long-term research on the influence of prolonged use of ways of the main tillage and fertilizer systems on the agroecological condition of the soil and productivity of two different in biology and an agrotechnology cultures: winter wheat and potatoes. The winter wheat does not make considerable demands to soil agrophysics. Due to forming of well-developed root mass this cereal crop improves properties and the modes of the soil, and continuous crops promote reduction of risk of erosion development [10]. Potatoes, on the contrary, are sensitive to an agrophysical condition of the soil and demand rich soils. It has the considerable potential of productivity, but is rather expensive culture [5]. Its cultivation makes the significant pressure upon the soil because of repeated and intensive loosening of the soil, influence of heavy machinery and fertilization [6]. In scientific literature positive aspects of impact of moldboardless tillage and application of nonconventional types of organic fertilizers on indicators of fertility of soils and productivity of cultures are widely covered [2, 3, 5, 6-9]. But also the delay of root growth on a shallow tillage is noted that is connected with deterioration in the water-air mode and sharp reduction of available moisture reserves [10]. Authors emphasize that insufficiently intensive loosening of a root-inhabited layer can cause forming of critical values of the soil physical properties and violation of root development of plants. Due to this, the research of elements' influence of soil-protective technologies on fertility indicators in specific soil-climatic conditions is an important component of ecologization of agrotechnologies and forming of steady agroecosystems $[6,7,8]$.

\section{Materials and methods}

In article the results of the final stage of scientific observations which were carried out on an experimental field of the Polissia national university (The Chernyakhiv district of the Zhytomyr region, Ukraine) in stationary research "Ecologically safe agrotechnologies" (STP "Ecologically Safe Agrotechnologies and Models of Land Use", number of the state registration 0107U003280) are generalized [6,8]. The scheme of research assumed comparison of the usage efficiency of traditional moldboard tillage (plowing on 18-20 cm was accepted as control) and moldboardless tillage (blade tillage on 18-20 cm) ways of the main tillage of soil. Also in the research the efficiency of different fertilizer systems with use in a crop rotation of collateral products and green manure crops was investigated [6]:

1. Without fertilizers - control.

2. A traditional organo-mineral fertilizer system which included introduction on 1 hectare of a crop rotation of $6.25 \mathrm{t}$ of manure and $\mathrm{N}_{50} \mathrm{P}_{48} \mathrm{~K}_{55}$.

3. An alternative organo-mineral fertilizer system (in a crop rotation: manure, $6.25 \mathrm{t} /$ hectare + straw, $1.25 \mathrm{t} /$ hectare $+\mathrm{N}, 12.5 \mathrm{~kg} /$ hectare (compensation of an immobilization of nitrogen at straw decomposition) + green manure, $5.62 \mathrm{t} / \mathrm{hectare}+$ $\mathrm{N}_{31} \mathrm{P}_{32} \mathrm{~K}_{36}$ ).

Manure and other types of organic fertilizers were brought under the main soil tillage (with preliminary disking) according to the scheme of research. As green manure afterharvest sowing of a yellow kind lupine Yantar was used.

Light gray forest soil of the research area has the low content of a humus $(1.10 \pm 0.07 \%)$, very low content of the hydrolyzed nitrogen $(58.5 \pm 10.7 \mathrm{mg} / \mathrm{kg}$ by Kornfield), high - labile phosphorus (138.1 mg/kg) and low - an exchangeable potassium (59 mg/kg by Kirsanov) [6]. Reaction is subacidic. 


\section{Results of a research}

The researches indicate advantage of moldboardless processing in optimization of structural aggregate state of the soil $[6,8]$. Prolonged moldboardless tillage (27 years) promoted the reduction of megastructural aggregates and the sprayed material (microstructure), having provided the increase of coefficient structure in an arable layer for $16.4 \%$ (without fertilizers, an average value for 3 years) in comparison with control (plowing). On options of technologies with fertilizers the indicator grew by $7.0-15.5 \%$. At the same time, the water resistance of units increased by 7.8-8.1\%, the soil hardness indicator decreased by $9.4 \mathrm{~kg} / \mathrm{cm}^{2}$ or $30 \%$ before potatoes planting, and before cropping the winter wheat - by $9.1 \mathrm{~kg} / \mathrm{cm}^{2}$ or $24 \%$ in comparison with plowing (options without fertilizers). Improvement of agrophysical indicators promoted optimization of water and physical indicators (reduction of losses of moisture from the soil layer of $0-10 \mathrm{~cm}$, reserves of productive moisture preservation in layers of 10-20 and 20-30 cm) [6]. So, the reserve of productive moisture in a layer of 0-30 $\mathrm{cm}$ exceeded an indicator on plowing on $7.0 \mathrm{~mm}$ or $19.8 \%$. By the end of vegetation the reserve of productive moisture on $4.4 \mathrm{~mm}$ or $14.2 \%$ was higher in comparison with plowing. In potato crops this pattern remained the same. So, before planting the culture on the background of moldboardless tillage in a layer of $0-30 \mathrm{~cm}$ the increase made $6.1 \mathrm{~mm}$ or $19.7 \%$, and before cropping $-3.4 \mathrm{~mm}$ or $12 \%$ in comparison with control [6].

It is also established that on options where moldboardless tillage was applied systematically (27 years), the maintenance of a humus significantly increased. So, without fertilization the increase made $24.4 \%$, and against the background of organo-mineral systems $-21.8-22.2 \%$. It corresponds to increase in energy potential of the soil (it is determined by power consumption of a humus) on control (without fertilization) at 5.8 $\mathrm{kcal} / \mathrm{kg}$, and on the fertilized soil fertilities - on 5.6-6.1 kcal $/ \mathrm{kg}$.

On average for 3 years of observations at a seedling stage in soil-protective agrotechnologies without fertilization on 1 sq. $\mathrm{m}$ of crops of a winter wheat the quantity of weeds was 18 pieces higher or $33.3 \%$ in comparison to control. At the same time the air-dry mass of weeds exceeded an indicator on control in $20.9 \%$. At the background of fertilization in such technologies the quantity of weeds was 14 pieces higher or $20.2 \%$ than on control [11]. At the same time, the air-dry mass of weeds exceeded control for $10.5 \%$. To shooting and heading the winter wheat effectively suppressed weeds. But for the period of its blossoming the influence of culture on weeds was a little weakened that contributed to growth and the development of summer late weeds - a Setaria glauca (L.) P. Beauv and Setaria viridis L. glauca. On unfertilized field the contamination of a winter wheat increased by 48 $50 \%$ before harvesting [11].

Before cropping the culture at options where soil-protective agrotechnologies were applied (without fertilizers), the quantity of weeds on 25 pieces/sq.m (31.3\%) was higher, than on plowing. The air-dry mass of weeds for $27.9 \%$ exceeded an indicator on control. In group structure the wintering and winter weeds (pic. 1) prevailed [11]. At the same time, the way of the main processing had no significant effect on a ratio between biological groups of weeds, though the tendency to increase the part of root-sprout (stolon) weeds and spring early weeds is noticeable [11]. 


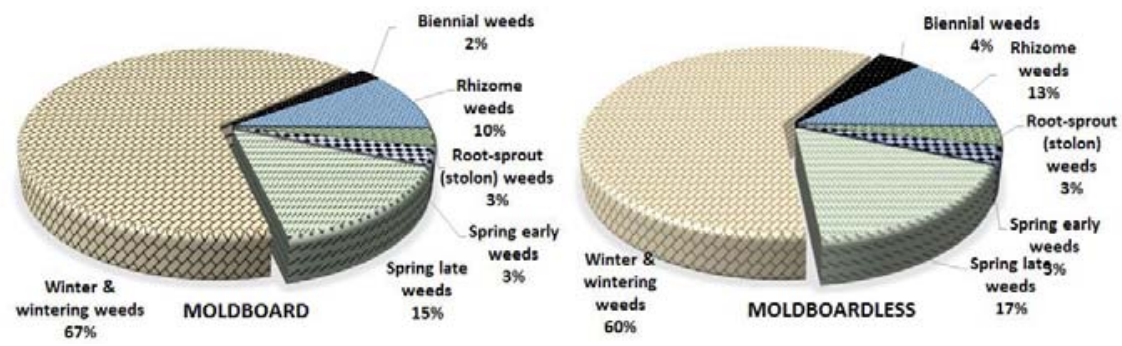

Fig. 1. Influence of a way of the main soil cultivation on a ratio between biological groups of weeds in crops of a winter wheat without fertilization (a stage of waxy ripeness, an average for 3 years) [11]

Significant increase in quantity of weeds (for $35.8 \%$ ) is recorded also in potato plantings. At the same time, the air-dry mass of weeds increased by $26.4 \%$.

It is worth emphasizing that the productivity of a winter wheat and potatoes at prolonged use of moldboardless processing was equivalent to control [6].

\section{Conclusions}

1. Transition to moldboardless tillage is an important element of increase of the agroecological condition of the soil and steady maintaining of agricultural production in the conditions of Polissia of Ukraine.

2. It is established that long following of technologies which are based on moldboardless tillage of soil in a crop rotation at options without fertilization on light gray forest soil in the conditions of Polissia provided improvement of structural aggregate state for $16.4 \%$, growth of water resistance of units by $7.8-8.1 \%$, reduction of hardness of the soil by $9.1-9.4 \mathrm{~kg} / \mathrm{cm}^{2}$.

3. It was recorded the reserves increase of productive moisture at the time of winter wheat crops in a layer of $0-30 \mathrm{~cm}-$ on $7.0 \mathrm{~mm}$ or $19.8 \%$, and before harvesting - on $4.4 \mathrm{~mm}$ or $14.2 \%$ in comparison to an indicator on plowing. In potato planting the advantage of moldboardless tillage remained the same: before planting of culture the increase made 6.1 $\mathrm{mm}$ or $19.7 \%$, and before cropping $-3.4 \mathrm{~mm}$ or $12 \%$ in comparison to control.

4. The productivity of a winter wheat and potatoes on average for 3 years of observations at prolonged use of moldboardless tillage was equivalent to plowing. However, in the research the significant increase of weeds quantity in crops of wheat (for $33.3 \%$ ), and potatoes is noted (for $35.8 \%$ ). At the same time, the air-dry mass of weeds increased by 20.9 and $26.4 \%$ respectively.

\section{References}

1. S. I. Veremeenko, Agroecological principles of assessment of condition and management of productivity of soils of the Western Polissia of Ukraine, 460 (1997)

2. M. A. Galich, V. P. Strelchenko, Agroecological bases of land use of Zhytomyr region, 184 (2004)

3. S. A. Balyuk, Bulletin of agrarian science, 6, 6 (2010)

4. B. I. Dibrov, Soils of Zhytomyr region, 59 (1969)

5. Sh. M. Powell, J. E. McPhee, G Dean, S. Hinton, et al, Soil research (2020)

6. M. Kravchuk, R. Kropyvnytskyi, V.Andryiash, V. Klymchuk, K. Mysko, Scientific horizons, 11(84), 61 (2019) 
7. Y. L. Chen, J. Palta, J. Clements, B. Buirchell, H. M. Kadambot, R. Z. Siddique, Field Crops Research, 165, 61 (2014)

8. M. M. Kravchuk, R. B. Kropyvnytskyi, L. L. Dovbysh, O. P. Yakovenko, Zb. sciences. pr. Nat. sciences. Center "Institute of Agriculture NAAS", 3-4, 12 (2016)

9. S. I. Veremeienko, L. O. Semenko, Naukovi horyzonty. «Scientific horizons», 1(74), 69 (2019)

10. G. Kadžienè, L. J. Munkholm, J. K. Mutegi, Geoderma, 166(1), 66 (2011)

11. M. Kravchuk, R. Kropivnitsky, V. Sanin, M. Botsyan, Naukovi horyzonty. «Scientific horizons», 7-8(70), 42 (2018)

12. Yu. V. Budonnyi, M. V. Shevchenko, Visnyk Lvivskoho DAU, 8, 67 (2004) 